\title{
Intracystic Haemorrhage in a Non-Endometriotic Mullerian Vaginal Cyst: An Unexpected Phenomenon
}

\author{
$\operatorname{Ng} \mathrm{BK}^{1}(\bowtie)$, Lim PS ${ }^{1}$, Shafiee $\mathrm{MN}^{1}$, Abdul Kadir AK ${ }^{1}$, Nordashima $\mathrm{AS}^{2}$, Omar $\mathrm{MH}^{1}$ \\ ${ }^{1}$ Department of Obstetrics and Gynaecology, ${ }^{2}$ Department of Pathology, Faculty of Medicine, Universiti \\ Kebangsaan Malaysia Medical Centre, Jalan Yaacob Latif, Bandar Tun Razak, 56000 Cheras, Kuala \\ Lumpur, Malaysia.
}

\begin{abstract}
We report a case of rare, Mullerian vaginal cyst with intracystic haemorrhage in the absence of endometrial components. To date, this is the second case reported in the literature. A 51-year-old post-menopausal woman with history of anterior vaginal wall cyst was misdiagnosed to have cystocele. The cyst was excised and the content was old blood mixed with mucous. Histopathological examination revealed a Mullerian vaginal cyst without endometrial component. Thus, diagnosis and management of vaginal cyst was revisited and discussed.
\end{abstract}

Keywords: $\quad$ endometrial, intracystic haemorrhage, Mullerian cyst, vaginal

\section{Correspondence:}

Ng Beng Kwang, Department of Obstetrics and Gynaecology, Faculty of Medicine, Universiti Kebangsaan Malaysia Medical Centre, Jalan Yaacob Latif, Bandar Tun Razak, 56000 Cheras, Kuala Lumpur, Malaysia. Tel: +603-91455949 Fax: +60391456672 Email: nbk_9955@yahoo.com,nbk9955@ppukm.ukm.edu.my

\section{Introduction}

Benign vaginal cystic lesions are relatively uncommon. The prevalence has been estimated around $0.5 \%$ but this was probably underestimated, as most of them were asymptomatic. Thus it was not reported (1). A retrospective study over 15 years in Athens showed that vaginal cyst constituted $37.5 \%$ of all vaginal lesions that were being diagnosed (2). Mullerian cyst was the most common type followed by Bartolin's, Gartner's and rarely endometriotic cyst (3). However, lesions arising from surrounding organs such as cystocele or urethrocele might be misleading. We described a vaginal cyst, which was misdiagnosed as cystocele initially. Excision of the vaginal cyst revealed a Mullerian cyst with intracystic haemorrhage in the absence of endometrial component.

\section{Case Report}

A 51-year-old Para 4 presented with history of mass per vagina for the past 20 years. She remained asymptomatic but started to have discomfort with occasional dyspareunia for six months duration. There was no urinary incontinence, abnormal vaginal discharge or bleeding. She had no history of perineal trauma. There was no significant past medical or surgical history. She had four uneventful full term vaginal deliveries.

She was first seen in a local clinic six months ago and was told to have mild cystocele, thus referred to us for further management. Physical examination revealed a non-tender $3 \mathrm{~cm}$ cystic mass at anterior vaginal wall just below the urethral meatus. Upward pressure on the cyst did not show leakage of urine through the urethral meatus. The remainder of pelvic examination was unremarkable with no cystocele or uterovaginal prolapse. The trans-abdominal ultrasound showed a hypoechoic cystic mass measuring $40 \times 25 \mathrm{~mm}$ in the vagina (Fig. 1a). Perineal ultrasound noted a $3 \mathrm{~cm}$ echogenic fluid filled cystic mass with no connection to the bladder or urethra (Fig. 1b). She was counseled regarding surgical excision, as she was symptomatic. 


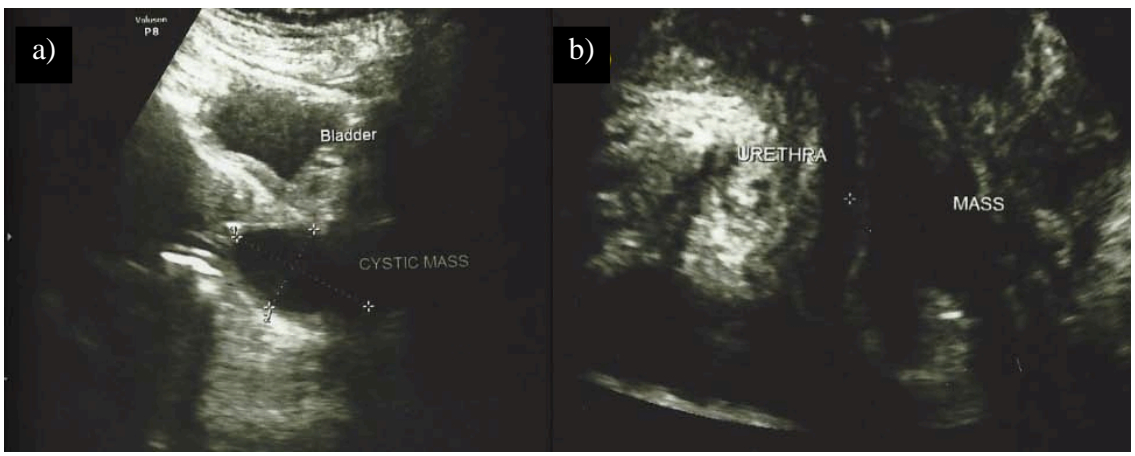

Figure 1: a) Trans-abdominal ultrasound showed a hypoechoic cystic mass measuring $40 \mathrm{x} 25 \mathrm{~mm}$ in the vagina; b) Perineal ultrasound noted a $3 \mathrm{~cm}$ echogenic fluid filled cystic mass anterior to the cervix with no connection to the bladder or urethra.

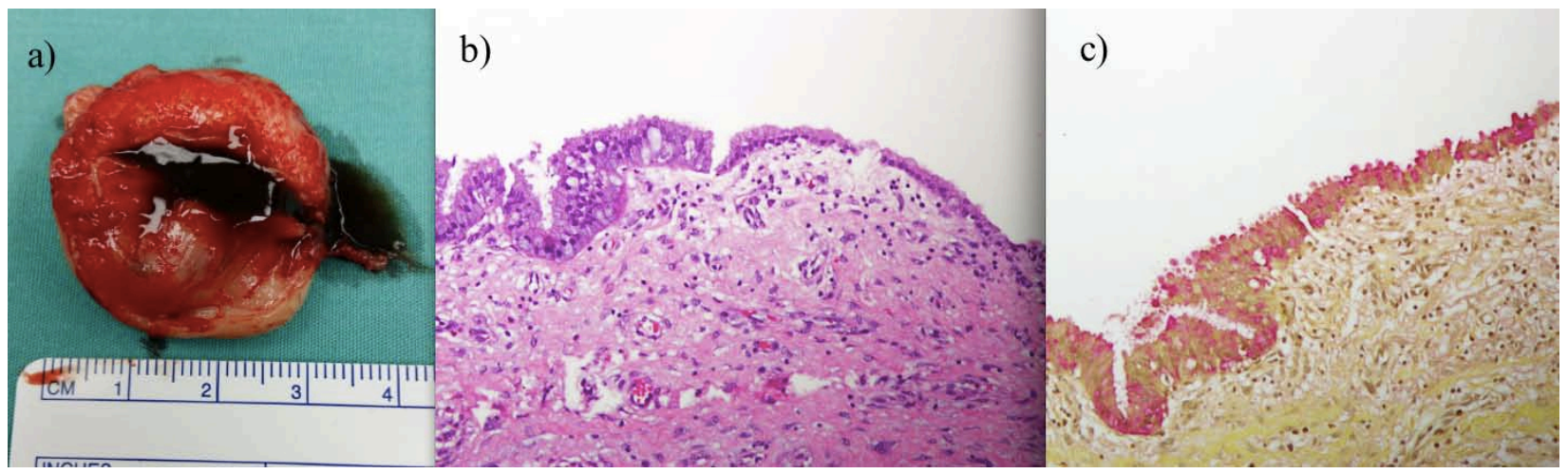

Figure 2: a) Specimen photo showed presence of blood and mucous after the cystic mass was incised; b) Photo-micrograph of the cyst wall lined by tall columnar secretory endocervical-type epithelium (H\&E: 200x); c) Mullerian cyst showing strong mucin staining with mucicarmine stain (200x).

Excision of the cyst was performed under regional anaesthesia. The cyst was excised in total with intact capsule. There was no communication with the urethra or bladder. When the cyst was cut open, approximately 4 mls of dark coloured old blood mixed with mucous was drained (Fig. 2a). Histopathological examination (HPE) of the cyst wall showed fibrovascular cyst wall lined by mucin secreting, tall columnar, endocervical type without evidence of endometrial tissue. There was no malignant cell seen (Fig. 2b, 2c).

\section{Discussion}

Vaginal cyst can be either congenital or acquired. Squamous inclusion cyst at site of previous surgery include episiotomy wound was the most common acquired vaginal cyst (4). Congenital cysts reflex complex embryonic origin with variety location. Vaginal cyst derived from upper vagina mainly due to remnants of Mullerian ducts (Mullerian cyst) and Wolffian duct (Gartner cyst) whereas lowermost portion of vagina derived from urogenital sinus (congenital vestibular cyst) (4). In addition, cystocele, urethrocele and urethral diverticulum from neighbouring structure might be misleading as vaginal cyst.

Mullerian cyst was the commonest vaginal cyst reported in most literature, (3,5,6,7,8,9) often as incidental findings, which explained the dearth of literature. However, patients could present with symptoms such as dyspareunia, stress urinary incontinence, pelvic pressure (10) or masquerading as a cystocele $(11,12)$. This patient was misdiagnosed as cystocele before referred to our centre. Thus, pelvic examination is of paramount important to ascertain the diagnosis.

A study by Pradhan and Tobon on 41 patients between 19 to 68 years with average age at 37.6 years revealed that postero-lateral wall of the vagina was the most common location for vaginal cyst $(5,7)$. The size ranged from 1.0 to $7.0 \mathrm{~cm}$ with average $2.8 \mathrm{~cm}$ (5). Other rare location of Mullerian cyst, like mediastinum, has been reported (13).

Additional radiological imaging might be necessary to identify the relation between the cyst and surrounding 
structures in order to facilitate the planning of surgical excision. Imaging modalities such as ultrasound scan and Magnetic Resonance Imaging (MRI) helps to identify the exact location, number of cyst, border, extent and communication with surrounding structures $(8,9)$. This patient had abdominal ultrasound scan that noted a hypoechoic cystic mass measuring 40 x $25 \mathrm{~mm}$ in the vagina. Perineal ultrasound scan showed a $3 \mathrm{~cm}$ echogenic fluid filled cystic mass with no connection to the bladder or urethra. We did not proceed with MRI as the mass was clearly seen with the ultrasound scan.

As discussed earlier, majority of Mullerian cyst was asymptomatic and small in size; therefore treatment was unnecessary. Occasionally, excision is warranted if the cyst is large or symptomatic. Histologically, Mullerian cyst was predominantly lined by mucinous epithelium; other epithelia of Mullerian origin i.e. endocervical, endometrial or fallopian type might be present (1). Malignancy arising from a vaginal Mullerian cyst had been reported (14). This patient's HPE was consistent with Mullerian cyst of endocervical type.

The finding of old blood in a vaginal cyst is clinically suggestive of endometriotic cyst. However, it was the least common type of vaginal cyst. Two out of three criteria must be seen during HPE for endometriotic vaginal cyst: endometrial glands, endometrial stromal and haemosiderin laden macrophages (1). The finding of blood illustrated by this case report remained unanswered. We postulated that local trauma (during intercourse) might be a factor as the cyst was existence for past 20 years but became symptomatic only for the past 6 months. Till date, this is the second case that was reported.

\section{Conclusion}

Vaginal Mullerian cyst is uncommon. Examination and pre-operative assessment is crucial to identify the location, extent and relationship with surrounding structure. Lastly, intracystic haemorrhage might occur in a simple vaginal Mullerian cyst without evidence of endometriosis.

\section{References}

1. Eilber KS, Raz S. Benign cystic lesions of the vagina: a literature review. J Urol 2003; 170(3): 717-22.

2. Kondi-Pafiti A, Grigoriadis C, Kalampokas T, Filippidou A, Salakos N, Hassiakos D. Clinicopathological study of 112 cases of benign, pre-invasive and invasive lesions of the vagina: a 15-year review. Eur J Gynaecol Oncol 2012; 33(5): 463-66.

3. Kondi-Pafiti A, Grapsa D, Papakonstantinou K, Kairi-Vassilatou E, Xasiakos D. Vaginal cyst: a common pathologic entity revisited. Clin Exp Obstet Gynecol 2008; 35(1): 41-4.

4. Heller DS. Vaginal cyst: a pathology review. J Low Genit Tract Dis 2012; 16(2): 140-44.

5. Pradhan S, Tobon H. Vaginal cysts: a clinicopathological study of 41 cases. Int J GtnecolPathol 1986; 5(1): 35-46.

6. Rivlin ME, Meeks GR, Ghafar MA, Lewin JR. Intracystic hemorrhage in a nonendometriotic Mullerian vaginal cyst. World J Clin Cases 2013; 1(1): 34-6.

7. Jayaprakash S, Lakshmidevi M, Kumar SG. A rare case of posterior vaginal wall cyst. BMJ Case Rep 2011; 2011.pii: bcr0220113804.

8. Hwang JH, Oh MJ, Lee NW, Hur JY, Lee KW, Lee JK. Multiple vaginal Mullerian cysts: a case report and review of literature. Arch Gynecol Obstet 2009; 280(1): 137-9.

9. Cil AP, Basar MM, Kara SA, Atasoy P. Diagnosis and management of vaginal Mullerian cyst in a virgin patient. Int Urogynecol J Pelvic Floor Dysfunct 2008; 19(5): 735-7.

10. Wai CY, Corton MM, Miller M, Sailors J, Schaffer JI. Multiple vaginal cysts: diagnosis and surgical treatment. Obstet Gynecol 2004; 103(5 Pt 2):1099-102.

11. Toz E, Sanci M, Cumurcu S, Ozcan A. Mullerian cyst of the vagina maswuerading as a cystocele. Case Rep Obstet Gynecol 2015; 2015: 376834.

12. Dilbaz B, Sengui O, dede S, Yerebasmaz N, Akkurt O. Prolapsing vaginal Mullerian cyst with cervical elongation mimicking cystocele. J Obstet Gynaecol 2014; 34(2): 212-13.

13. Kobayashi S, Inoue $\mathrm{T}$, Kaarube $\mathrm{Y}$, et al. A case of Mullerian cyst arising in posterior mediastinum. Ann Thorac Cardiovasc Surg 2012; 18(1): 39-41. 
14. Lee KS, Park KH, Lee S, Kim JY, Seo SS. Adenocarcinoma arising in a vaginal Mullerian cyst: a case report. Gynecol Oncol 2005; 99(3): 767-9. 